\title{
Prevalence of Anemia Among Women Receiving Antenatal Care at Boditii Health Center, Southern Ethiopia
}

\author{
Dereje Lelissa $^{1}$, Matiyas Yilma ${ }^{1}$, Weldesenbet Shewalem ${ }^{1}$, Amanuel Abraha $^{2}$, Mesfin Worku ${ }^{1}$, \\ Henock Ambachew ${ }^{1}$, Misganaw Birhaneselassie ${ }^{1,}$ \\ ${ }^{1}$ Hawassa University College of Medicine and Health Sciences, Department of Medical Laboratory; Hawassa, Ethiopia \\ ${ }^{2}$ Orebro University School of Health and Medical Sciences, Department of Clinical Medicine, Örebro, Sweden
}

\section{Email address:}

misganawbs@gmail.com (M. Birhaneselassie)

\section{To cite this article:}

Dereje Lelissa, Matiyas Yilma, Weldesenbet Shewalem, Amanuel Abraha, Mesfin Worku, Henock Ambachew, Misganaw Birhaneselassie. Prevalence of Anemia Among Women Receiving Antenatal Care at Boditii Health Center, Southern Ethiopia. Clinical Medicine Research. Vol. 4, No. 3, 2015, pp. 79-86. doi: 10.11648/j.cmr.20150403.14

\begin{abstract}
Background: Anemia is regarded as a major risk factor for unfavorable outcome of pregnancy both for the mother and the fetus. Methodology: A heath center based cross-sectional study was conducted in Boditii Health Centers from April 12 to June 23, 2012. Data was collected using pretested questionnaire, which contains socioeconomic, demographic and clinical characteristics of pregnant women shown to have association with anemia. A total of 125 pregnant women were enrolled in this study. HGB was measured using the Sahli-Hellinge method of HGB determination. Data was entered and statistical analysis was performed using SPSS version 16, software. Association between variables was done using chi square, and statistical significance was considered at $\mathrm{P}$ value $<0.05$. Result: The prevalence of anemia obtained in this study was 77/125 $(61.6 \%)$, based on the WHO criterion for the diagnosis of anemia in pregnancy, i.e. hemoglobin $<11.0 \mathrm{~g} / \mathrm{dl}(\mathrm{PCV}<33 \%)$. In terms of severity, mild anemia was present in 41(53.2\%) of women, moderate anemia was present in $36(46.8 \%)$, and there were no cases of severe anemia. The prevalence of anemia in this study was $58.4 \%$ and $41.5 \%$ for primigravida and multigravida, respectively $(\mathrm{P}<0.05)$. Anemia was also found to increase as the gestational age increases, showing the highest prevalence in the third trimester (46.7\%) than second (45.4\%) and first trimester $(7.8 \%),(\mathrm{P}<0.001)$. Conclusion and Recommendation: From our results, we can conclude that anemia in pregnant women was highly prevalent in Boditti town. Our study revealed that the prevalence of anemia is higher in primigravidea than multigravidea. Anemia also increased as the gestational age increases. Intervention including health education about causes of anemia and its risk factors and antenatal care (ANC) follow up should be improved.
\end{abstract}

Keywords: Anemia, Antenatal Care, Pregnant Women

\section{Introduction}

Anemia is a global public health problem. It affects approximately 2 billion people of the world wide (1). It occurs as a result of deficiencies of essential nutrients, heavy blood loss, parasitic infections or increased requirements including those seen in pregnancy $(1,2)$.

Fifty six percent of pregnant women and $43 \%$ of nonpregnant women in developing countries are anemic while only $18 \%$ of women in developed countries are believed to be anemic $(3,4)$. Prevalence of anemia during pregnancy in developing countries is relatively high $(33 \%-75 \%)(5,6)$, while $15 \%$ of pregnant women are anemic in developed countries (3-7).
Anemia is the most common nutritional deficiency disorder in the world (8) and the most common cause worldwide is iron deficiency (6). The predisposing factors include grand multiparity, low socioeconomic status, maternal infection, late prenatal care, HIV infection and inadequate spacing of children (9).

Anemia is regarded as a major risk factor for unfavorable outcomes of pregnancy (10) both for the mother and the fetus. Studies have shown that the adverse consequences of maternal anemia may affect not only the neonate but also increase the risk of non-communicable disease as the neonate grows into an adult and may contribute to the risk of low birth weight in the next generation (11). Anemia has been associated with premature labour and low birth weight (10) 
and maternal and prenatal 1 mortality (12). Fetal mortality has consistently been associated with maternal mortality (13).

Antenatal care services, although not as strong in health institutions in Ethiopia as in the developed world, these services are the main mechanism for safe motherhood interventions and are believed to reduce maternal and perinatal mortality. In Ethiopia, $66 \%$ of pregnant women attend the ANC clinic once per pregnancy $(4,14)$.

Intervention measures are planned and improved based on available information regarding the magnitude and severity of anemia, and associated risk factors in the geographic area. Therefore, the objective of this study was to assess the prevalence of anemia among pregnant women attending ANC at Boditti Health Center, southern Ethiopia and to identify factors that contribute to the presence and severity of anemia.

\section{Methodology}

\subsection{Study Setting}

A heath center based cross-sectional study was conducted in Boditii Health Center from April 12 to June 23, 2012. Boditti is a town located in SNNPR of Ethiopia, with a distance of $770 \mathrm{~km}$ from the capital city of Ethiopia (Addis Ababa), $140 \mathrm{~km}$ from the regional state university (Hawassa) and $16 \mathrm{~km}$ from zonal center Wolayta. The source population was all pregnant women in Damot Gale woreda, Wolaita zone, Boditii town. The study population included all pregnant women attending the antenatal care (ANC) clinic at Boditii Health Center. Pregnant women who came for ANC during the study period were included as study participants.

\subsection{Data Collection}

Data was collected using a pretested questionnaire, which contains socioeconomic, demographic and clinical characteristics of pregnant women shown to have association with anemia. The questionnaire was developed by the CBE (Community Based Education) office of Hawassa University College of Medicine and Health Sciences, adopted and modified for the purpose of this study. Data was collected by practicing laboratory technologists under the supervision of senior staff. A total of 125 pregnant women were enrolled in this study.

Blood samples were collected from all study participants. The HGB value was determined and the severity of anemia was noted based on the HGB value according to the WHO definition as mild, moderate and severe anemia (15). HGB was measured using the Sahli - Hellinge method of HGB determination. In this study, anemia in pregnancy was defined as $\mathrm{HGB}<11 \mathrm{~g} / \mathrm{dl}$. Mild, moderate and severe anemia was defined as HGB measurements between 10-10.9 g/dl, 7$9.9 \mathrm{~g} / \mathrm{dl}$ and less than $7 \mathrm{~g} / \mathrm{dl}$, respectively (16). Anemic pregnant women were immediately referred to the attending health professionals at the ANC clinic of the health center for treatment and follow up.

\subsection{Data Analysis}

Data was entered and statistical analysis was performed using SPSS version 16, software. Association between variables was done using chi square, and statistical significance was considered at $\mathrm{P}$ value $<0.05$.

\subsection{Ethical Consideration}

Ethical approval was obtained from the Institution Review Board (IRB) of Hawassa University College of Medicine and Health Sciences, and the solicitation to participate letter was submitted to the administration of the health center from the department of medical laboratory sciences. The consent of the study participants was ensured and confidentiality was maintained.

\section{Result}

The study involved a total of 125 pregnant women who attended ante natal care (ANC) at Boditii Health Center, southern Ethiopia. The mean $\pm \mathrm{SD}$ age of the women was $23.8 \pm 4.0$ with a range of 17-34 years. Half of the participants were home makers and $56(49 \%)$ of them were educated at the elementary education level. Most of the women included in this study were from the rural areas and earned lower level incomes per month (Table 1).

Table 1. Socioeconomic and demographic characteristics of pregnant women attending ANC at Boditii Hhealth Center from April 12 to June 23, 2012 .

\begin{tabular}{|c|c|c|}
\hline Characteristics & frequency & percent \\
\hline \multicolumn{3}{|l|}{ Age } \\
\hline $15-19$ & 25 & 20 \\
\hline $20-24$ & 44 & 35 \\
\hline $25-29$ & 46 & 37 \\
\hline $30-34$ & 10 & 8 \\
\hline \multicolumn{3}{|l|}{ Kebele [area] } \\
\hline Chewkare & 26 & 21 \\
\hline Dige & 21 & 17 \\
\hline Gido & 31 & 25 \\
\hline Hagera & 30 & 24 \\
\hline Kuke & 17 & 14 \\
\hline \multicolumn{3}{|l|}{ Occupation } \\
\hline Gov employee & 17 & 14 \\
\hline Merchant & 12 & 10 \\
\hline Maid & 5 & 4 \\
\hline Student & 29 & 23 \\
\hline House wife & 62 & 50 \\
\hline \multicolumn{3}{|l|}{ Education level } \\
\hline Illiterate & 12 & 10 \\
\hline Literacy campaign & 1 & 1 \\
\hline Elementary school & 56 & 45 \\
\hline Secondary school & 27 & 21 \\
\hline Higher education & 29 & 23 \\
\hline \multicolumn{3}{|c|}{ Monthly income ( Eth birr) } \\
\hline$<150$ & 11 & 9 \\
\hline $151-500$ & 34 & 27 \\
\hline $501-850$ & 30 & 24 \\
\hline $851-1200$ & 32 & 26 \\
\hline$>1200$ & 18 & 14 \\
\hline
\end{tabular}


Among all pregnant women, $52.8 \%$ of them were multigravida and $47.2 \%$ were primigravida. A majority of the women $(81.8 \%)$ had birth spacing of more than two years. A majority of the women had no chronic disease in previous pregnancies and had no diseases on admission to the clinic, $88 \%$ and $92 \%$ respectively. Over half of the pregnant women $64(51 \%)$ were in their second trimester of pregnancy, and $70 \%$ of them used supplementary drugs such as iron supplements in their pregnancy (Table 2).

The overall prevalence of anemia in this study was $77 / 125$ $(61.6 \%)$. In terms of severity, mild anemia was 41(53.2\%), moderate anemia was $36(46.8 \%)$, and there was no severe anemia identified (Fig 1). The severity of anemia was distributed among respondents' characteristics; moderate anemia was more common in women of multigravida $(23.3 \%)$, in women of $\geq 2$ years of birth spacing $(50 \%)$, and in women who do not take supplement drugs (16.9\%) (Fig 2) (Table 3). Mild anemia was more common in primigravida $(35.1 \%)$, in first $(6.5 \%)$ and second $(23.3 \%)$ trimester of pregnancy, and in women taking supplement drugs $(41.5 \%)$ (Fig 2) (Table 3).
Table 2. Clinical characteristics of pregnant women attending ANC at Boditii Health Center from April 12 to June 23, 2012.

\begin{tabular}{lll}
\hline Characteristics & frequency & percent \\
\hline Gravidity & & \\
Primigravida & 59 & 47.2 \\
Multigravida & 66 & 52.8 \\
Birth spacing & & \\
$<2$ years & 12 & 18.2 \\
$>2$ years & 54 & 81.8 \\
Chronic disease in previous pregnancy & & \\
Yes & 8 & $12.1 \%$ \\
No & 58 & $87.8 \%$ \\
Current disease & & \\
Yes & 10 & $8 \%$ \\
No & 115 & $92 \%$ \\
Trimester & & \\
First & 19 & 15 \\
Second & 64 & 51 \\
Third & 42 & 34 \\
Supplement taking & & \\
Yes & 87 & 70 \\
No & 38 & 30 \\
\hline
\end{tabular}

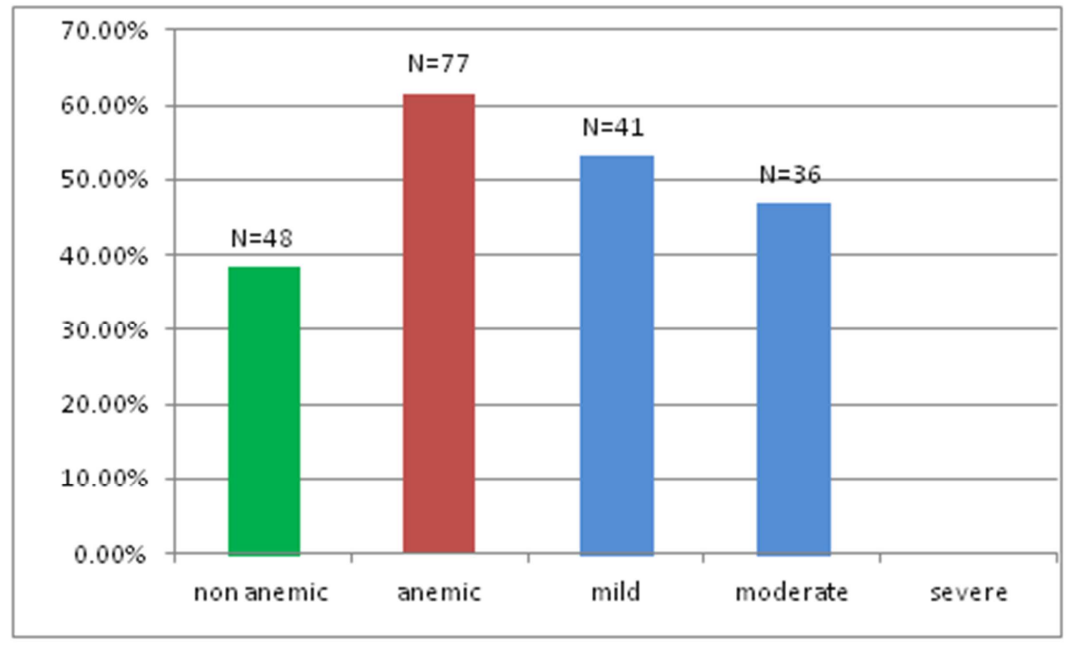

Fig. 1. Prevalence and severity of anemia in women attending ANC at Boditii Health Center from April 12 to June 23, 2012.

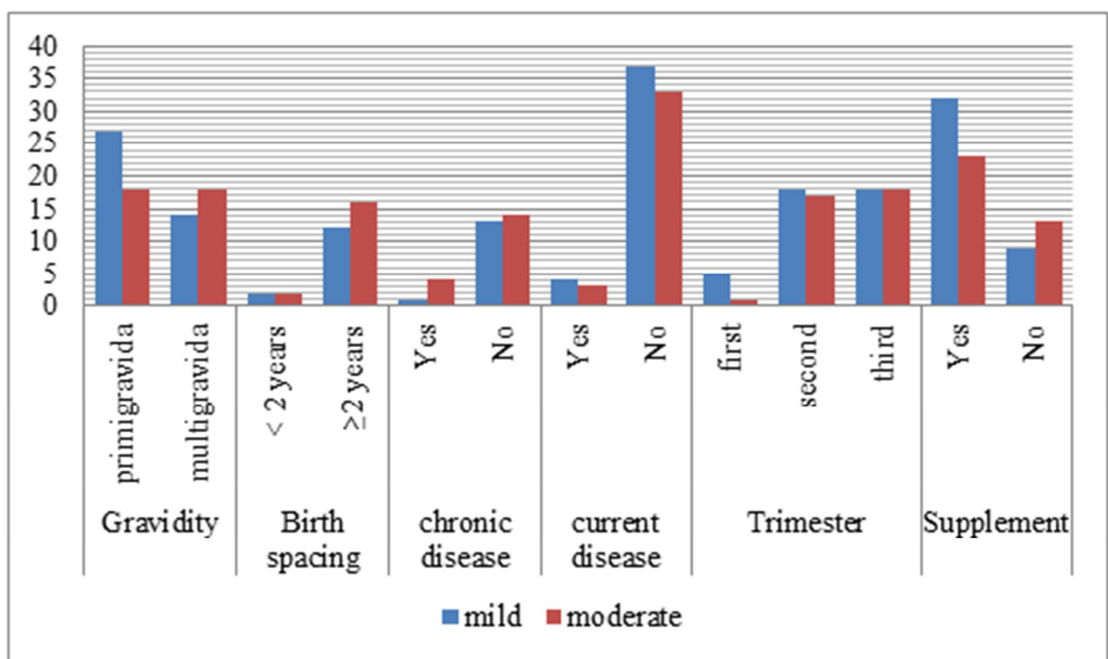

Fig. 2. Clinical characteristics and severity of anemia in women attending ANC at Boditii Health Center from April 12 to June 23, 2012. 
Table 3. Socioeconomic, demographic and clinical characteristics of women with severity of anemia attending ANC at Boditii Health Center from April 12 to June 23, 2012.

\begin{tabular}{|c|c|c|c|c|c|}
\hline & \multicolumn{4}{|c|}{ Hemoglobin level ( g/dl) } & \multirow{2}{*}{$P$ - value } \\
\hline & Non anemic $(n=48)$ & Anemic $(n=77)$ & & & \\
\hline Age & Above 11 & Mild (10-11) & Moderate (7-9.9) & Total anemic N (\%) & \multirow{6}{*}{$\mathrm{P}>0.05$} \\
\hline $15-19$ & $5(10.4 \%)$ & $11(14.3 \%)$ & $9(11.6 \%)$ & $20(25.9)$ & \\
\hline $20-24$ & $19(39.6 \%)$ & $14(18.2 \%)$ & $11(14.3 \%)$ & $25(32.5)$ & \\
\hline $25-29$ & $21(43.8 \%)$ & $15(19.5 \%)$ & $10(12.9 \%)$ & $25(32.5)$ & \\
\hline $30-34$ & $3(6.3 \%)$ & $1(1.3 \%)$ & $6(7.8 \%)$ & $7(9.1)$ & \\
\hline \multicolumn{5}{|l|}{ Occupation } & \\
\hline Gov employee & $10(20.8 \%)$ & $4(5.2 \%)$ & $3(3.8 \%)$ & $7(9)$ & \multirow{5}{*}{$\mathrm{P}>0.05$} \\
\hline Merchant & $3(6.3 \%)$ & $7(9.1 \%)$ & $2(2.6 \%)$ & $9(11.6)$ & \\
\hline Maid & $1(2.1 \%)$ & $1(1.3 \%)$ & $3(3.8 \%)$ & $4(5.2)$ & \\
\hline Student & $7(14.6 \%)$ & $11(14.3 \%)$ & $11(14.3 \%)$ & $22(28.5)$ & \\
\hline House wife & $27(56.2 \%)$ & $18(23.3 \%)$ & $17(22.1 \%)$ & $35(45.4)$ & \\
\hline \multicolumn{5}{|l|}{ Education level } & \multirow{6}{*}{$\mathrm{P}>0.05$} \\
\hline Illiterate & $5(10.4 \%)$ & $3(3.8 \%)$ & $4(5.2 \%)$ & $7(9.1)$ & \\
\hline Literacy campaign & 0 & 0 & $1(1.3 \%)$ & $1(1.3)$ & \\
\hline Elementary school & $20(41.7 \%)$ & $24(31.1 \%)$ & $12(15.5 \%)$ & $36(46.7)$ & \\
\hline Secondary school & $10(20.8 \%)$ & $8(10.3 \%)$ & $9(11.6 \%)$ & $17(22.1)$ & \\
\hline Higher & $13(27.1 \%)$ & $6(7.7 \%)$ & $10(13 \%)$ & $16(20.7)$ & \\
\hline \multicolumn{5}{|l|}{ Monthly income } & \multirow{9}{*}{$\mathrm{P}<0.05$} \\
\hline$<150$ & $3(6.3 \%)$ & $6(7.7 \%)$ & $2(2.6 \%)$ & $8(10.3 \%)$ & \\
\hline $151-500$ & $10(20.8 \%)$ & $12(15.5 \%)$ & $12(15.5 \%)$ & $24(31.1)$ & \\
\hline $501-850$ & $14(29.2 \%)$ & $6(7.7 \%)$ & $10((13 \%)$ & $16(20.7)$ & \\
\hline $851-1200$ & $16(33.3 \%)$ & $10(13 \%)$ & $6(7.7 \%)$ & $16(20.7)$ & \\
\hline$>1200$ & $5(10.4 \%)$ & $7(9.1 \%)$ & $6(7.7 \%)$ & $13(16.8)$ & \\
\hline \multicolumn{5}{|l|}{ Gravidity } & \\
\hline Primigravida & $14(29.2 \%)$ & $27(35.1 \%)$ & $18(23.3 \%)$ & $45(58.4)$ & \\
\hline Multigravida & $34(70.8 \%)$ & $14(18.2 \%)$ & $18(23.3 \%)$ & $32(41.5)$ & \\
\hline Birth spacing & & & & & \multirow{4}{*}{$\mathrm{P}>0.05$} \\
\hline$<2$ years & $8(16.7 \%)$ & $2(6.2 \%)$ & $2(6.2 \%)$ & $4(12.5)$ & \\
\hline$\geq 2$ years & $26(54.2 \%)$ & $12(37.5 \%)$ & $16(50 \%)$ & $28(87.5)$ & \\
\hline \multicolumn{5}{|c|}{ Chronic disease in previous pregnancy } & \\
\hline Yes & $3(6.2 \%)$ & $1(3.1 \%)$ & $4(12.5 \%)$ & $5(15.6)$ & \multirow{2}{*}{$\mathrm{P}>0.05$} \\
\hline No & $31(64.6 \%)$ & $13(40.6 \%)$ & $14(43.7 \%)$ & $27(84.3)$ & \\
\hline \multicolumn{5}{|l|}{ Current disease } & \multirow{3}{*}{$\mathrm{P}>0.05$} \\
\hline Yes & $3(6.2 \%)$ & $4(5.2 \%)$ & $3(3.9 \%)$ & $7(9.1)$ & \\
\hline No & $45(93.8 \%)$ & $37(48.0 \%)$ & $33(42.8 \%)$ & $70(90.9)$ & \\
\hline \multicolumn{5}{|l|}{ Trimester } & \multirow{4}{*}{$\mathrm{P}<0.001$} \\
\hline First & $13(27.1 \%)$ & $5(6.5 \%)$ & $1(1.3 \%)$ & $6(7.8)$ & \\
\hline Second & $29(60.4 \%)$ & $18(23.3 \%)$ & $17(22.1 \%)$ & $35(45.4)$ & \\
\hline Third & $6(12.5 \%)$ & $18(23.3 \%)$ & $18(23.3 \%)$ & $36(46.7)$ & \\
\hline \multicolumn{5}{|l|}{ Supplement taking } & \multirow{3}{*}{$\mathrm{P}>0.05$} \\
\hline Yes & $32(66.7 \%)$ & $32(41.5 \%)$ & $23(29.8 \%)$ & $55(71.4)$ & \\
\hline No & $16(33.3 \%)$ & $9(11.7 \%)$ & $13(16.9 \%)$ & $22(28.6)$ & \\
\hline
\end{tabular}

Approximately $26 \%, 32.4 \%, 32.4 \%$ and $9 \%$ of the pregnant women who were in age range of 15-19, 20-24, 2529 and 30-34 years were anemic, respectively. Nearly half of the women with anemia were home makers, and had been educated at the elementary (Table 3 ).

The prevalence of anemia in this study was $58.4 \%$ and $41.5 \%$ for primigravida and multigravida, respectively $(\mathrm{P}<0.05)$. Anemia was also found to increase as the gestational age increases, showing the highest prevalence in the third trimester $(46.7 \%)$ then the second trimester $(45.4 \%)$ and first trimester $(7.8 \%),(\mathrm{P}<0.001)$. Women with birth interval of greater than or equal to two years showed more prevalence of anemia (87.5\%) than those with an interval of less than two years $(12.5 \%)$. On the other hand, anemia was reported more commonly in women who didn't have chronic disease in a previous pregnancy $(84.3 \%)$ and in women who didn't have current disease during pregnancy (90.9\%), and in women taking supplementary drugs (71.4\%) (Table 3).

Among the primigravida ( $\mathrm{N}=59)$ mothers, $27(45.8 \%)$ were home makers, and $28(47.5 \%)$ were educated at the elementary level. Among 66 (52.8\%) multigravida, 54(81.8\%) had child spacing greater than 2 years and 12(18.2\%) had birth spacing of less than two years. Of all the multigravida, $32(48.5 \%)$ had received ANC services during their previous pregnancies and $34(51.5 \%)$ did not receive ANC services during their previous pregnancies (data not shown).

Among 34(51.5\%) pregnant women who did not receive ANC services during their previous pregnancies, 22(64.7\%) respondents identified their reason for this as they were not informed about it, $7(20.6 \%)$ reported the absence of a health 
institution, $3(8.8 \%)$ said because they were not willing to receive ANC services and $2(5.9 \%)$ cited financial reasons. In the multigravidae, only $8(12.1 \%)$ had chronic disease in their previous pregnancies, and among them 6 had hypertension and 2 had diabetes mellitus. However, of all the pregnant women, only 10 had current disease of which 6 had malaria, 3 had typhoid fever and 1 mother had another disease (data not shown).

\section{Discussion}

The prevalence of anemia obtained in this study was $(61.6 \%)$, based on WHO criterion for the diagnosis of anemia in pregnancy, i.e. hemoglobin $<11.0 \mathrm{~g} / \mathrm{dl}(\mathrm{PCV}<33 \%)(15)$. This finding is high but comparable with other local studies carried out in different parts of Ethiopia. In a study undertaken in the Gilgel Gibe dam area, $(53.9 \%)$ of pregnant woman were anemic in Asendabo (62.7\%), and in Jimma (57\%) anemia prevalence was reported in pregnant women attending ANC clinics (17-19). Similar findings were also reported in eastern Sudan (62.6\%) and China (70\%); India also reported a higher result than this study (92.39\%) (20-22).

However, the prevalence of anemia reported in pregnant women showed variability both locally and in other countries A study conducted in south East Ethiopia (Harar) showed prevalence of anemia as $27.9 \%$, and in Gondar $(23.2 \%)$ anemia prevalence which were much lower findings from the report obtained in this study (23-24). Other countries, also reported a similarly low prevalence of anemia in pregnant women, Nigeria $(23.2 \%)$, Thailand (14\%), unlike this study (25-26).

Globally, many studies reported different socioeconomic, demographic and clinical characteristics of pregnant woman that may affect the magnitude of anemia (27). Anemia was associated with aspects of lower socioeconomic class such as low level of education, rural residence, not working or manual worker, low reported income. Other clinical characteristics such as gravidity, regular ingestion of iron supplements, trimester of pregnancy, and other factors are shown to be risk factors for anemia (27-31).

In addition, the accuracy of the HGB measurement used should be taken in to account. In this study, the HGB value of the pregnant woman was done by the old comparative Sahli Hellinge method, which is subjected to biases in dilution and reading of results. Nevertheless, the result obtained in this study was consistent with the characteristics of the study population, and findings from other regional and international reports. The majority of the study subjects involved in this study were rural residents from different catchment areas of Boditii town. Studies conducted to identify risk factors of anemia in pregnant women have found strong association of rural residence with anemia. In ANC services, pregnant women who were from rural areas were more than three times more likely to be anemic than their urban counterparts $(23,24)$.

According to the WHO classification, 41(53.2\%) of anemic pregnant women had mild anemia (HGB 10-11g/dl) and nearly half of the anemic women had moderate anemia (HGB 7-9.9 $\mathrm{g} / \mathrm{dl}$ ), in this study. Other studies in Ethiopia, reported a mild anemia ranging from $23 \%$ to $81 \%$, and moderate anemia from $17.9 \%$ to $74.3 \%$. This finding is comparable with studies in other countries, $(19,33,34)$. The study reported in this paper, however, differs in that it didn't identify any cases of severe anemia.

The present study and other studies in Ethiopia indicated that moderate anemia constitutes a significant portion of anemia in pregnant women attending ANC clinics. In fact, moderate anemia causes considerable consequences such as loss of energy and function for these women. Activities such as child care and household management as well as job performance are affected. They are more vulnerable to infections and improvement from infections may be prolonged. The anemia can also result in risks to the mother and newborn $(22,35,36)$. Therefore, increased health education on risk factors and interventions to prevent the prevalence and severity of anemia among pregnant women should be a priority for mothers attending ANC.

In this study it was identified that anemia was significantly higher in the primigravidae and third trimester of pregnancy. This is consistent with other studies conducted in sub Saharan Africa. This study reported a statistically significant association between anemia and primigravida women, where the prevalence of anemia in primigravida was higher $(35.1 \%)$ than in multigravida $(18.2 \%),(\mathrm{P}<0.05)$. Similar reports have also been found in other studies $(15,37,38)$.

This study also reported, an association of gestational age with anemia statistically significant for the third trimester, $(\mathrm{P}<0.001)$. Anemia was shown to increase from first $(7.8 \%)$ to second (45.4\%) and to third $(46.7 \%)$ trimester of pregnancy. This report is consistent with the work of others in Ethiopia and Nigeria $(33,34,39)$. Overall, this study demonstrated a high prevalence of anemia and described its severity among groups. The study also identified at risk groups of pregnant women for targeted intervention. For example, more focus must be given for primigravida women than multigravida and for women in the third trimester of pregnancy in ANC follow up.

\section{Conclusion and Recommendation}

From our result we can conclude that anemia is highly prevalent in Boditti town. Our study revealed that the prevalence of anemia is higher in primigravidea than multigravidea women. The severity of anemia also increased as the gestational age increased. Intervention including health education about causes of anemia and its risk factors and ANC follow-up should be given top priority.

\subsection{Limitation}

The study had limited sample size in relation to other studies and the method used to measure hemoglobin level was Sahli Tube method which can result in personal bias during comparing with the standard. 


\section{Acknowledgement}

We heartedly acknowledge the staff and administration of
Boditii Health Center for their cooperation and permission to use the laboratory for the study. Our sincere thanks also go to Linda Fell for reviewing the manuscript.

\section{Appendix}

\section{Hawassa University College of Medicine and Health Science}

Medical Laboratory Sciences Department

\section{Prevalence of Anemia Among Women Attending Ante Natal Care at Health Center}

Part 1. socio demographic and economic characteristics of the respondent.

1. Code No

2. Address : Region Age

3. Occupation

$\square$ Government employee $\square$. Merchant $\square$ Maid $\square$ Student

$\square$ House wife $\square$ Bartender $\square$ Others specify

4. Educational level

$\square$ Illiterate $\square$ Literacy campaign $\square$ Elementary School

$\square$ Secondary school $\square$ Higher level

5. What is your monthly income (in average) in birr?

$\square$ Below $150 \square 151-500 \square 501-850 \square 851-1200 \square$ Above 1201

Part 2. knowledge and associated factors of anemia.

6. Is this your first pregnancy? $\square$ Yes $\square$ No

7. If no to No 7, how many times have you been pregnant?

$\square 1 \square 2 \square 3 \square 4 \square$ Above 5

8. What is the duration of time you waited between pregnancies?

$\square$ Less than two years $\square$ Greater than two years.

9. Did you follow ANC during your previous pregnancies?

$\square$ Yes $\square$ No

10. If no to No 10 why?

$\square$ You were not informed about it $\square$ Absence of health institution near your house.

$\square$ You were not willing $\square$ Financial problem $\square$ Others (specify)

11. Was there any chronic disease in the previous pregnancies?

$\square$ Yes $\square$ No

12. If yes to No 11 what was the disease? Specify.

13. Do you have any disease now?

$\square$ Yes $\square$ No

14. If yes to No 14 specify

15. Do you know about anemia?

$\square$ Yes $\square$ No

16. If yes to No 16, how do you think it's caused? Specify

17. Do you take supplements during your pregnancies?

$\square$ Yes $\square$ No

Part 3. Laboratory Test.

18. Hemoglobin level of the respondent 


\section{References}

[1] Mlean E, Conges M, Egli I, Wojdyla D, Debendit B. Worldwide prevalence of anemia: WHO vitamin and mineral nutrition information system:1993 -2005: Public Health Nutr.2008:12(14): 444- 54.

[2] Allen LH, anemia an iron deficiency effects on pregnancy outcome. Am. J.Clini.Nutr.2000; 71:1285.

[3] Stoltsfus R.J. Iron deficiency: global reference and consequences Food. Nutr. Bull.2003; 24(4):99-103.

[4] Untro J, Cross R, Schultire W, Sidiaoetama D. The association between BMI and hemoglobin and work productivity among Indonesian female factors workers. Eureapian.J.Clini.Nutr.1998; 52: 131-133.

[5] World Health Organization. The prevalence of anemia in women: a tabulation of available information. Geneva Switzerland: WHO: 1992; WHO/NCH/MSM/ 92-2.

[6] Nbuke RB, letsky EA: Etiology of anemia in pregnancy in south Malawi.Am.J.Clini.Nutr.2000; 72:247 - 256.

[7] World Health Organization (WHO) prevention and management of sever anemia in pregnancy: report of technical working group. Geneva - Sweizerland: WHO 1993: WHO /FNE/MSM/ 93.5.

[8] Demayer EM: Tegman A. prevalence of anemia in the world. World Health Organization Qlty 1998; 38:302 - 16.

[9] Vanden brock NR, Progrsion SI, Mahango CJ, et al. Anemia in pregnancy in southern Malawi: prevalence and risk factor. BIOG. 2000; 107: 437-435.

[10] Barbin et al. consequence of maternal Anemia on outcome of pregnancy in malaria endemic areas in Papua New Guinea. Am.Trop.med parasitol 1990; 84 : 11-24.

[11] Kalirini. Prevalence and consequences of anemia in pregnancy. Department of biomedicine National Institute of Health and family welfare, New Delhi, India J.Med.Res 130, November 2009: P 627- 633.

[12] Rasmusens. First and second trimester hemoglobin levels in relation to birth weight and gestational age .Act A Obstet. Gyneacol. Scand. 1993; 72: 246 -251.

[13] Ryoh D. Nutritional and maternal mortality in developing world. Am. J. Clini. Nutr.2000, 72: 212 -240.

[14] Gebremedhin M, Birgyard G. serum ferritin in Ethiopian mothers and their new born infants in relation to iron intake and socio economic conditions. Scand J Haematol. 1981 Oct; 27(4):247-52.

[15] World Health Organization (WHO). The prevalence of Anaemia in women: A tabulation of available information. Geneva, Switzerland: WHO; 1992. WHO/MCH/MSM/92.2.

[16] WHO: Hemoglobin Concentrations for the Diagnosis of Anemia and Assessment of Severity. Vitamin and Mineral Nutrition Information System. Geneva: World Health Organization; 2011. http://www.who.int/vmnis/ indicators/haemoglobin.pdf, accessed [01May, 2014].
[17] Million Getachew, Delenesaw Yewhalaw, Ketema Tafess, Yehenew Getachew and Ahmed Zeynudin Anaemia and associated risk factors among pregnant women in Gilgel Gibe dam area, Southwest Ethiopia. Parasites \& Vectors 2012, 5:296.

[18] Yonas T: Prevalence of anaemia among ANC attendants of Assendabo Teaching Health Center. Jimma, Ethiopia: MSc thesis. Jimma Institute of Health Sciences; 1996.

[19] Desalegn S. Prevalence of anaemia in pregnancy in Jima town, southwestern Ethiopia. Ethiop Med J. 1993 Oct; 31(4):251-8.

[20] Adama I, Khamis AH, Elbashir MI: Prevalence and risk factors for anemia in pregnant women of eastern Sudan. Trans R Soc Trop Med Hyg 2005, 99(10):739-743.

[21] Xing Y, Yan H, Dang S, Zhuoma B, Zhou X, et al. Hemoglobin levels and anemia evaluation during pregnancy in the highlands of Tibet: a hospital-based study.BMC Public Health 2009, 9: 336

[22] K. Kalaivani. Prevalence \& consequences of anaemia in pregnancy. Indian J Med Res 130, November 2009, pp 627633

[23] Filagot Kefiyalew, Endalew Zemene, Yaregal Asres and Lealem Gedefaw. Anemia among pregnant women in Southeast Ethiopia: prevalence, severity and associated risk Factors. BMC Research Notes 2014, 7:771.

[24] Alem M, Enawgaw B, Gelaw A, Kena T, Seid M, Olkeba Y: Prevalence of anemia and associated risk factors among pregnant women attending antenatal care in azezo health center Gondar town, northwest Ethiopia. J Interdiscipl Histopathol 2013, 1:137-144.

[25] Oboro VO, Tabowei TO, Jemikalajah J. Prevalence and risk factors for anaemia in pregnancy in South Southern Nigeria. J Obstet Gynaecol 2002, 22: 610- 613.

[26] Sukrat B, Suwathanapisate P, Siritawee S, Poungthong T, Phupongpankul K. The prevalence of iron deficiency anemia in pregnant women in Nakhonsawan, Thailand. J Med Assoc Thai 2010, 93: 765-770.

[27] Elashirya, El ghazali S, Habil I. Prevalence and determinants of anaemia in third trimester pregnancy in fayoum governorate-Egypt. Acta Medica Mediterranea, 2014, 30: 1045

[28] Jin L, Yeung LF, , Cogswell ME, Ye R, Berry RJ, Liu J, Hu DJ, Zhu L. Prevalence of anaemia among pregnant women in south-east China, 1993-2005. Public Health Nutr 2010; 13(10): 1511-8.

[29] Ahmad N, Kalakoti P, Bano R, Aarif SMM. The prevalence of anaemia and associated factors in pregnant women in a rural Indian community. AMJ 2010; 3:276-80.

[30] Belachew T, Legesse Y. Risk factors for anemia among pregnant women attending antenatal clinic at Jimma University Hospital, southwest Ethiopia. Ethiop Med J 2006, 44: $211-220$.

[31] Federal Ministry of Health. Planning and Programming Department Health and health related indicators. Addis Ababa: Planning and Programming Department, Federal Ministry of Health, Government of Ethiopia, Ethiopia. 2004, 54: 58. 
[32] Oboro VO, Tabowei TO, Jemikalajah J. Prevalence and risk factors for anaemia in pregnancy in South Southern Nigeria. J Obstet Gynaecol 2002, 22: 610- 613.

[33] Alemayehu Hailu Jufar, Tewabech Zewde Prevalence of Anemia among Pregnant Women Attending Antenatal Care at Tikur Anbessa Specialized Hospital, Addis Ababa Ethiopia. Hematol Thromb Dis 2014, 2:1

[34] Olujimi A. Olatunbosun, Aniekan M. Abasiattai, Emem A. Bassey, Robert S. James, Godwin Ibanga, and Anyiekere Morgan. Prevalence of Anaemia among Pregnant Women at Booking in the University of Uyo Teaching Hospital, Uyo, Nigeria. BioMed Research International Volume 2014, Article ID 849080.

[35] Prema K, Neela Kumari S, Ramalakshmi BA. Anaemia and adverse obstetric out come. Nutr Rep Int 1981; 23: 637-43.
[36] Bukar M, Audu BM, Yahaya UR, Melah GS. Anaemia in pregnancy at booking in Gombe, North-eastern Nigeria. J Obstet Gynaecol 2008; 28:775-8.

[37] World Health Organization (WHO). The prevalence of Anaemia in women: A tabulation of available information. Geneva, Switzerland: WHO; 1992. WHO/MCH/MSM/92.2.

[38] Adesina Olubukola, Akinyemi Odunayo, Oladokun Adesina Anemia in pregnancy at two levels of health care in Ibadan, south west Nigeria Annals of African Medicine, Vol. 10, No. 4, October-December, 2011, pp. 272-277.

[39] Niguse O, Mossie A, Gobena T: Magnitude of anemia and associated risk factors among pregnant women attending antenatal care in shalla woreda, west arsi zone, oromia region, Ethiopia. Ethiop J Health Sci 2013, 23:165-173. 